\title{
Fabrication and Characterization of Chitosan Based Injectable Thermosensitive Hydrogels Containing Silica/Calcium Phosphate Nanocomposite Particles
}

\author{
Seyed Mohsen Latifi ${ }^{1}$, Christina Tang ${ }^{2}$, Henry J. Donahue ${ }^{{ }^{*}}$ \\ ${ }^{1}$ Bone Engineering Science and Technology (BEST) Lab, Department of Biomedical Engineering, Virginia Commonwealth \\ University, Richmond, VA, USA \\ ${ }^{2}$ Department of Chemical and Life Sciences Engineering, Virginia Commonwealth University, Richmond, VA, USA \\ Email: ^hjdonahue@vcu.edu
}

How to cite this paper: Latifi, S.M., Tang, C. and Donahue, H.J. (2021) Fabrication and Characterization of Chitosan Based Injectable Thermosensitive Hydrogels Containing Silica/Calcium Phosphate Nanocomposite Particles. Journal of Biomaterials and Nanobiotechnology, 12, 34-48.

https://doi.org/10.4236/jbnb.2021.123004

Received: June 1, 2021

Accepted: July 25, 2021

Published: July 28, 2021

Copyright $\odot 2021$ by author(s) and Scientific Research Publishing Inc. This work is licensed under the Creative Commons Attribution International License (CC BY 4.0).

http://creativecommons.org/licenses/by/4.0/

(c) (i) Open Access

\begin{abstract}
In this study, the effect of silica/calcium phosphate ( $\mathrm{SiCaP}$ ) nanocomposite particles on the properties of a novel chitosan-based thermosensitive hydrogel system was examined. SiCaP nanocomposite powder was fabricated using a sol-gel method and then used to fabricate nanocomposite hydrogels (Ch$\beta / 7.5 \mathrm{SiCaP}$ and $\mathrm{Ch}-\beta / 15 \mathrm{SiCaP}$ ) including chitosan and $\beta$-glycerophosphate $(\mathrm{Ch}-\beta)$ as a matrix. Results revealed that compared to the $\mathrm{Ch}-\beta$ hydrogel without $\mathrm{SiCaP}$, the presence of $\mathrm{SiCaP}$ particles in nanocomposite hydrogels maintained $\mathrm{pH}$ stability during the sol-gel transition, accelerated the gelation and improved the stiffness of nanocomposite hydrogels. Gelation time at $37^{\circ} \mathrm{C}$ was reduced approximately $75 \%$ and stiffness was increased approximately $115 \%$. Both of these changes are attributed to chemical and physical interactions of the SiCaP bioactive particles with chitosan. Furthermore, compared to the $\mathrm{Ch}-\beta$ hydrogel, the presence of $\mathrm{SiCaP}$ in the $\mathrm{Ch}-\beta / 7.5 \mathrm{SiCaP}$ nanocomposite hydrogel did not affect biocompatibility negatively, but improved osteoblastic cell differentiation. Our studies suggest that these nanocomposite hydrogels may offer an innovative approach to bone regeneration strategies.
\end{abstract}

\section{Keywords}

Thermosensitivity, Composite Hydrogel, Bioactive Particles, Rheology, Biocompatibility 


\section{Introduction}

Hydrogel is a water-insoluble, three-dimensional network of polymer chains capable of holding large amounts of water. Hydrogels that form in situ have attracted increasing attention in recent years for their potential biomedical applications [1]. Advantages of using hydrogels that form in situ include minimally invasive implantation, the ease with which they can be handled by surgeons, and better formation within irregular defects [2]. A thermogelling system including chitosan (Ch) and $\beta$-glycerophosphate ( $\beta$ ) was first reported by Chenite et al. [3] [4], prompting numerous studies on its properties and biomedical applications [1] [5]. It has been reported that Ch- $\beta$ hydrogels containing $0.5 \%-2 \%(\mathrm{w} / \mathrm{v})$ chitosan and $5 \%-20 \%(\mathrm{w} / \mathrm{v}) \beta$ display thermosensitive behavior [2]. Because of the role of $\beta$ in the molecular mechanism of gelation [1] [3] [5], increasing $\beta$ concentration in $\mathrm{Ch}-\beta$ hydrogels decreases both the gelation temperature [3] and time at $37^{\circ} \mathrm{C}$ [2] [6]. However, increasing the $\beta$ concentration has a negative effect on its biocompatibility as only extracts of $\mathrm{Ch}-\beta$ hydrogels with less than $10 \%(\mathrm{w} / \mathrm{v}) \beta$ display sufficient biocompatibility [2] to be useful in vivo. Therefore, $\beta$ concentration has both positive and negative effects on the final properties of Ch- $\beta$ hydrogels that should be considered when developing Ch- $\beta$ hydrogels for tissue regeneration applications.

Additional concerns regarding use of injectable Ch- $\beta$ hydrogels, especially for bone regeneration, include weak bioactivity and low mechanical strength. Hydroxyapatite (HA) has been widely used in biomedical application due to its similar chemical composition to human bone and teeth. However, slow degradation rates and modest bioactivity are limiting factors in using HA in novel bone regeneration strategies. Slow degradation limits release of $\mathrm{Ca}$ and $\mathrm{P}$ ions, both of which are important to bone regeneration. Additionally, the surface chemistry of HA has not been optimized for enhancing cell activity, including attachment and proliferation. Incorporating silica/calcium phosphate ( $\mathrm{SiCaP}$ ) nanocomposites, which have a higher dissolution rate and bioactivity than hydroxyapatite [7] [8], into Ch- $\beta$ hydrogels may enhance bone formation in vivo due to release of calcium and phosphorous ions [9] [10] from SiCaP nanocomposites. Moreover, the presence of silica in SiCaP nanocomposites may improve chemical bonding between apatite and polymer matrices [11] [12] thus enhancing mechanical properties of Ch- $\beta$ hydrogels. Therefore, we examined the hypothesis that the introduction of silica/calcium phosphate nanocomposite powder into Ch- $\beta$ hydrogels results in thermosensitive injectable composite hydrogel which has faster gelation time and improved mechanical properties after gelation at body temperature $\left(37^{\circ} \mathrm{C}\right)$ without any negative effect on its biocompatibility.

\section{Materials and Methods}

\subsection{Synthesis of Silica/Calcium Phosphate Nanocomposite Powder}

Silica/calcium phosphate ( $\mathrm{SiCaP}$ ) nanocomposite powder was fabricated using, 
with some modification, a previously described sol-gel technique [7]. Briefly, $15.775 \mathrm{~g}$ of calcium nitrate tetrahydrate $\left(\mathrm{Ca}\left(\mathrm{NO}_{3}\right)_{2} \cdot 4 \mathrm{H}_{2} \mathrm{O}, \mathrm{MW}: 236.15 \mathrm{~g} / \mathrm{mol}\right.$, Sigma-Aldrich, USA) was dissolved in an absolute ethanol to form a $1.67 \mathrm{~mol} / \mathrm{L}$. $2.839 \mathrm{~g}$ of phosphoric pentoxide ( $\mathrm{P}_{2} \mathrm{O}_{5}, \mathrm{MW}: 141.94 \mathrm{~g} / \mathrm{mol}$, Sigma-Aldrich, USA) was also dissolved in an absolute ethanol to form a $0.5 \mathrm{~mol} / \mathrm{L}$. Both of these prepared solutions were mixed at a $\mathrm{Ca} / \mathrm{P}$ molar ratio of 5:3. The resultant solution was then stirred for $24 \mathrm{~h}$ at room temperature and aged for $24 \mathrm{~h}$ at room temperature. Following this process, $2.738 \mathrm{ml}$ of tetraethylorthosilicate (TEOS, $\mathrm{C}_{8} \mathrm{H}_{20} \mathrm{O}_{4} \mathrm{Si}$, MW: $208.33 \mathrm{~g} / \mathrm{mol}$, Sigma-Aldrich, USA) was added to the aged mixture under continuous stirring. After $1.5 \mathrm{~h}$ of stirring, the final mixture was aged for $8 \mathrm{~h}$ at room temperature. The resulting gel was then dried at $80^{\circ} \mathrm{C}$ for $24 \mathrm{~h}$, and the dry powder was then crushed using a ball mill. Finally, the calcination of the crushed dry powder was carried out at $600^{\circ} \mathrm{C}$ for $30 \mathrm{~min}$, after which time the prepared powder was cooled at room temperature.

\subsection{Alkaline Treatment of Chitosan}

Chitosan (Product number: C3646, Sigma-Aldrich, USA) was exposed to alkaline treatment to increase the amine group content of chitosan as previously described [13], but with some modification. Briefly, chitosan powder was treated in $50 \%(\mathrm{~W} / \mathrm{V})$ sodium hydroxide solution for $30 \mathrm{~min}$ at $100^{\circ} \mathrm{C}$ under air. After washing 4 times with distilled water under vacuum, the chitosan powder was dried in a convection oven at $80^{\circ} \mathrm{C}$ for $48 \mathrm{~h}$. The obtained chitosan was used for hydrogel fabrication.

\subsection{Fabrication of Hydrogels}

To fabricate hydrogels, different percentages $\left(0 \%, 7.5 \%, 15 \% ; \mathrm{W}_{\mathrm{SiCaP}} / \mathrm{W}_{\text {chitosan }}\right)$ of $\mathrm{SiCaP}$ nanocomposite powder were dispersed ultrasonically in $0.1 \mathrm{~N}$ acetic acid. Chitosan $(2 \% \mathrm{w} / \mathrm{v})$ was then added to this solution and stirred overnight. After that, a $\beta$-glycerophosphate disodium salt hydrate $\left(\mathrm{C}_{3} \mathrm{H}_{7} \mathrm{Na}_{2} \mathrm{O}_{6} \mathrm{P} \cdot \mathrm{xH}_{2} \mathrm{O}, \mathrm{MW}: 216.04\right.$ $\mathrm{g} / \mathrm{mol}$, Sigma-Aldrich, USA) solution $(7.5 \% \mathrm{w} / \mathrm{v})$ was prepared in deionized water and added dropwise to the solutions, then magnetically stirred in an ice bath for $30 \mathrm{~min}$. The final products were filtered and stored at $4{ }^{\circ} \mathrm{C}$. Prepared hydrogels with $0 \%, 7.5 \%$, and $15 \% \mathrm{SiCaP}$ nanocomposite powder are denoted as $\mathrm{Ch}-\beta$, Ch- $\beta / 7.5 \mathrm{SiCaP}$, and Ch $-\beta / 15 \mathrm{SiCaP}$, respectively.

\subsection{Characterization of SiCaP Nanocomposite Powder and Treated Chitosan}

Scanning electron microscopy (Hitachi FE SEM Su-70) was used to evaluate the morphology of the $\mathrm{SiCaP}$ nanocomposite powder after sputter coating with platinum. Additionally, an energy dispersive X-ray spectrometer (EDX) was used to identify the chemical composition of the SiCaP nanocomposite powder. Functional groups in chitosan after treatment in sodium hydroxide solution were evaluated by Fourier transform infrared spectroscopy (FTIR, Nicolet-Nexus 670 
FT-IR). The $\mathrm{pH}$ of acidic solutions $(0.1 \mathrm{~N}$ acetic acid) with or without $\mathrm{Si} / \mathrm{CaP}$ nanocomposite powders at room temperature was determined.

\subsection{Characterization of Hydrogels}

\subsection{1. pH Value Measurement}

The $\mathrm{pH}$ of hydrogels was measured at $4^{\circ} \mathrm{C}$ and during the gelation process at $37^{\circ} \mathrm{C}$ and temperature was controlled by a water bath.

\subsubsection{Rheological Experiment}

The temperature at which hydrogel solutions gel, the time it takes for the hydrogels to gel at $37^{\circ} \mathrm{C}$, and mechanical strength of hydrogels at $37^{\circ} \mathrm{C}$ were evaluated using a DHR-3 stress-controlled rheometer (TA instruments, USA) in oscillatory mode with a $20 \mathrm{~mm}$ steel parallel plate geometry and temperature-controlled Peltier plate. Gelation was monitored using small-amplitude dynamic oscillatory temperature or time sweeps. The mechanical properties of the resulting gel were determined using a frequency sweep.

For each evaluation, ungelled hydrogel $(0.5 \mathrm{~mL})$ was loaded with a gap height of $\sim 1550 \mu \mathrm{m}$. A strain sweep test was first applied on the samples to define the linear viscoelastic region, where storage (elastic) modulus ( $\left.G^{\prime}\right)$ and loss (viscous) modulus $\left(G^{\prime \prime}\right)$ are independent of strain amplitude. Therefore, the strain amplitude was set as $0.4 \%$ for all measurements. To evaluate gelation temperature, $G^{\prime}$ and G" moduli were quantified while changing the temperature at a rate of $1^{\circ} \mathrm{C}$ $\min ^{-1}$ from $25^{\circ} \mathrm{C}$ to $45^{\circ} \mathrm{C}$ at a frequency of $1 \mathrm{~Hz}$. To evaluate gelation time, $\mathrm{G}^{\prime}$ and $\mathrm{G}^{\prime \prime}$ moduli were quantified at $37^{\circ} \mathrm{C}$ at a frequency of $1 \mathrm{~Hz}$. The temperature and the time at the cross point of $G^{\prime}$ and $G^{\prime \prime}$ were defined as the gelation temperature and the gelation time, respectively [14]. In order to estimate the stiffness of the gels, frequency independent $G^{\prime}$ and $G^{\prime \prime}$ moduli of gels were quantified in the frequency range between 0.1 and $10 \mathrm{~Hz}$ at $37^{\circ} \mathrm{C}$ (data not shown). For all gel conditions, the loss modulus was approximately 20 to 30 -fold, depending on the hydrogel composition, lower than the storage modulus, indicative of the elastic behavior of the hydrogels after gelation $\left(G \sim G^{\prime}\right.$ when $\left.G^{\prime \prime} \ll G^{\prime}\right)$ [15] [16]. Therefore, a stable plateau of $G^{\prime}$ in the response was used to estimate shear modulus (G). Then, the shear modulus was converted to Young's modulus (E) using rubber elasticity theory, $E=2 \mathrm{G}(1+v)$ with assuming $v=0.5$ [15] [16].

\subsubsection{Cytotoxicity Evaluation}

\section{1) Preparation of the extraction liquid of hydrogels}

Leachates were extracted according as previously described [17], but with some modification. $1.7 \mathrm{~mL}$ of each hydrogel solution was first added to 6-well cell culture plates and incubated at $37^{\circ} \mathrm{C}$. After gel formation, the hydrogels were washed for $10 \mathrm{~min}$ with PBS and twice for $10 \mathrm{~min}$ with DMEM/F12. Hydrogel extracts were obtained by adding to each hydrogel or culture plate only (control), $8 \mathrm{~mL}$ of DMEM/F12 with $10 \% \mathrm{FBS}$ at $37^{\circ} \mathrm{C}$ for 3 days. The extracts were filtrated with a $0.22 \mu \mathrm{m}$ filter and $1 \%$ Antibiotic-Antimyotic was added. 


\section{2) MTT assay}

To evaluate cytotoxicity of prepared hydrogels, human fetal pre-osteoblastic cells (hFOB 1.19) were seeded in 48-well culture plates at a density of $15 \times 10^{3}$ cells/well and cultured in DMEM/F12 with 10\% FBS and 1\% Antibiotic-Antimyotic for $24 \mathrm{~h}$ at $37^{\circ} \mathrm{C}$ and $5 \% \mathrm{CO}_{2}$. The media was then replaced by the extracts. Cell proliferation was quantified by MTT assay (TACS ${ }^{\oplus}$ XTT Cell Proliferation Assay) and absorbance measured at $570 \mathrm{~nm}$ with a microplate reader (Bio Rad, iMark) after 1,3 , and 5 days.

\section{3) Alkaline phosphatase (ALP) activity}

To evaluate in vitro osteogenic differentiation, $1.7 \mathrm{~mL}$ of each sol was first added to 6-well culture plates and incubated at $37^{\circ} \mathrm{C}$. After gel formation, the hydrogels were washed three times for $10 \mathrm{~min}$ with DMEM/F12. Hydrogel extracts were obtained by adding to each hydrogel or culture plate only (control), 8 $\mathrm{mL}$ of DMEM/F12 with $10 \% \mathrm{FBS}$ at $39.5^{\circ} \mathrm{C}$ for 4 days. The extracts were then filtrated with a $0.22 \mu \mathrm{m}$ filter and $1 \%$ Antibiotic-Antimyotic, $10^{-8} \mathrm{M}$ menadione, $100 \mu \mathrm{g} / \mathrm{mL}$ ascorbic acid, and $10^{-8} \mathrm{M}$ 1,25-dihydroxy vitamin $\mathrm{D}_{3}$ were added. hFOB 1.19 cells were seeded in 48-well culture plates at a density of $5 \times 10^{4}$ cells/well and cultured in proliferation media for $24 \mathrm{~h}$ at $33.5^{\circ} \mathrm{C}$ and $5 \% \mathrm{CO}_{2}$. The media was then replaced by the extracts and plates were transferred to $39.5^{\circ} \mathrm{C}$. Alkaline phosphatase (ALP) activity, an indicator of osteoblastic cell differentiation, was quantified after 2 and 7 days by assessing the conversion of p-nitrophenyl phosphate to p-nitrophenol. Absorption was measured at $415 \mathrm{~nm}$, and the specific enzyme activity was estimated from a p-nitrophenol standard curve after normalization to total protein content by BCA assay at $560 \mathrm{~nm}$.

\subsection{Statistical Analysis}

Quantitative data are expressed as means \pm standard deviation from at least three independent experiments. Statistical comparisons were carried out using analysis of variance (ANOVA) followed by Tukey's post hoc test. P values $<0.05$ were considered significant.

\section{Results and Discussion}

\subsection{Morphology and EDAX Analysis of SiCaP Nanocomposite Powder}

Figure 1(a) shows the morphology of the sol-gel derived SiCaP nanocomposite powder after calcination at $600^{\circ} \mathrm{C}$. Based on the scale bar of SEM image, the obtained powder is composed of agglomerated crystallites $(\sim 30 \mathrm{~nm})$. The ultrasonic dispersion of $\mathrm{SiCaP}$ nanocomposite powder during the fabrication of composite hydrogels breaks these agglomerations into smaller particles. This nanostructured morphology of SiCaP composite powder is important as it may improve osteoblast adhesion [18]. The presence of $\mathrm{Si}, \mathrm{Ca}, \mathrm{P}, \mathrm{O}$, and $\mathrm{C}$ elements in the SiCaP nanocomposite powder was confirmed via EDAX analysis (Figure 1(b)). As previously reported [7] [8], carbon (C) and silicon (Si), in the form of 

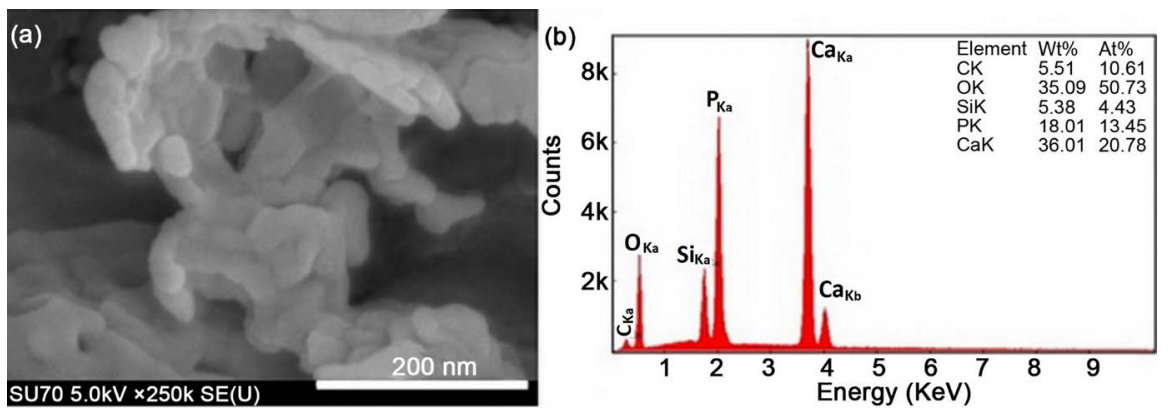

Figure 1. (a) SEM image and (b) EDAX analysis of sol-gel derived Si/CaP nanocomposite powder after calcination at $600^{\circ} \mathrm{C}$.

carbonate and silicate, respectively, were incorporated into the hydroxyapatite structure. Moreover, extra silicon in the form of an amorphous silica layer led to surface modification of apatite (carbonate and silicate co-doped hydroxyapatite). This surface and structural modification of hydroxyapatite are important as it can improve dissolution rate and bioactivity of hydroxyapatite [8]. Moreover, surface modification of apatite with a silica layer can improve the chemical interaction of SiCaP nanocomposite with matrix of nanocomposite hydrogels.

\subsection{FTIR Analysis}

The amino group $\left(-\mathrm{NH}_{2}\right)$ in chitosan has an important role in the thermogelling process of Ch- $\beta$ hydrogels [4]. To increase amino group content in chitosan, chitosan powder was subjected to deacetylation. As a result of this deacetylation process, only a complete amino group remains due to the elimination of an acetyl group from the molecular chain of chitosan [19]. Figure 2 shows the FTIR spectrum obtained from the chitosan after the deacetylation process in sodium hydroxide solution for $30 \mathrm{~min}$ at $100^{\circ} \mathrm{C}$.

A broad and strong band in the region $3285-3357 \mathrm{~cm}^{-1}$ is attributed to extension vibration of $\mathrm{N}-\mathrm{H}$, stretching vibration of $-\mathrm{OH}$, and intermolecular hydrogen bonds. The bands at 2919 and $2870 \mathrm{~cm}^{-1}$ correspond to $\mathrm{C}-\mathrm{H}$ symmetric and asymmetric stretching vibrations, respectively [20] [21]. The bands at 1646 and $1320 \mathrm{~cm}^{-1}$ are assigned to the $\mathrm{C}=\mathrm{O}$ stretching of amide $\mathrm{I}$ and $\mathrm{C}-\mathrm{N}$ stretching of amide III which are related to residual $\mathrm{N}$-acetyl groups [20]. Moreover, a band at $1593 \mathrm{~cm}^{-1}$ is attributed to $\mathrm{N}-\mathrm{H}$ bending vibrations for primary amine groups [20] [21]. The bands at 1418, 1374, and $1149 \mathrm{~cm}^{-1}$ are attributed to $\mathrm{CH}_{2}$ bending vibrations, $\mathrm{CH}_{3}$ symmetrical deformations, and asymmetric stretching of the $\mathrm{C}-\mathrm{O}-\mathrm{C}$ bridge, respectively. $\mathrm{C}-\mathrm{O}$ stretching vibration was confirmed by the bands at 1053 and $1023 \mathrm{~cm}^{-1}$ [20]. Also, the bands at 1257 and $892 \mathrm{~cm}^{-1}$ were attributed to bending vibrations of $-\mathrm{OH}[20]$ [21] and $\mathrm{C}-\mathrm{H}$ bending vibration out of the plane of the ring of monosaccharides [20], respectively.

All bands in Figure 2 were in agreement with the structure of chitosan [20], which indicates that the deacetylation process on chitosan did not have a negative effect on its structure. Moreover, this process not only improves the thermosensitivity of chitosan [6], but also its biocompatibility [22]. 


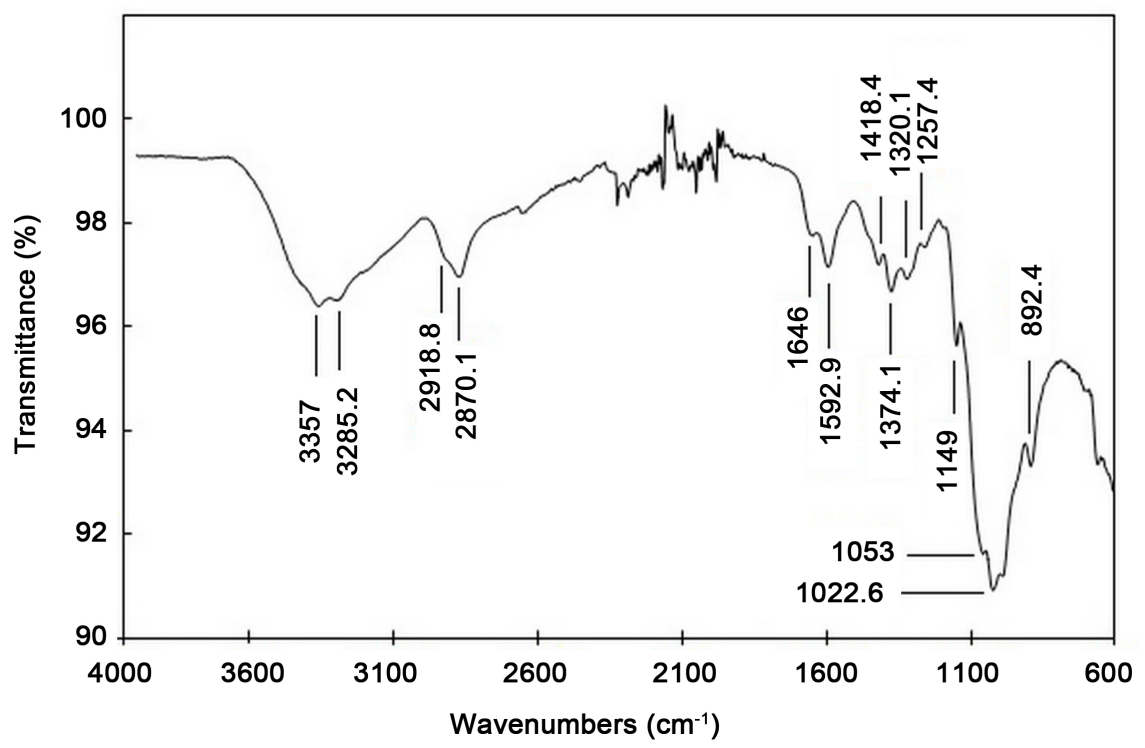

Figure 2. FTIR spectrum of the chitosan after treatment in sodium hydroxide solution for $30 \mathrm{~min}$ at $100^{\circ} \mathrm{C}$.

\subsection{Hydrogel Fabrication Process}

To distribute bioactive particles (SiCaP nanocomposite powder) in the matrix of nanocomposite hydrogels, the particles were first ultrasonically dispersed in acetic acid solution. As a result, the amount of undissolved chitosan slightly increased due to the increased SiCaP bioactive particles. This is due to the partial dissolution of bioactive particles in the acetic acid solution. In other words, the partial dissolution of bioactive particles in the acetic acid solution increases the $\mathrm{pH}$ value of an acidic solution as a result of consuming protons (Table 1). Chitosan dissolves in weak acidic solutions by protonation of its amine groups [23]. Therefore, the increase the $\mathrm{pH}$ value of the acidic solution increases the amount of undissolved chitosan through decreasing the protonation of chitosan amine groups.

\section{4. pH Measurement}

Figure 3 shows $\mathrm{pH}$, as a function of time, of prepared hydrogels during the sol-gel transition process at $37^{\circ} \mathrm{C}$. $\mathrm{pH}$ values of all the prepared hydrogels demonstrated a decreasing trend during the gelation process. Moreover, addition of bioactive particles ( $\mathrm{SiCaP}$ nanocomposite powder) into hydrogels did not change the $\mathrm{pH}$, relative to $\mathrm{Ch}-\beta$ hydrogel, of nanocomposite hydrogels during the sol-gel transition. The average $\mathrm{pH}$ values of all three prepared hydrogels, for 0 to 25 minutes, were in the range of $6.81-7.30$, which is physiologically acceptable and is one of the crucial conditions for the use of biomaterials in tissue regeneration [24].

\subsection{Gelation Temperature}

Figure 4(a) shows the gelation temperature of prepared hydrogels. The gelation 
Table 1 . The $\mathrm{pH}$ changes of acidic solution by adding Si/CaP nanocomposite powder $(\mathrm{n}=$ $3, \mathrm{p}<0.05)$.

\begin{tabular}{cc}
\hline Sample & $\mathrm{pH}$ \\
\hline Acidic solution $(0.1 \mathrm{~N}$ acetic acid $)$ & $2.82 \pm 0.01$ \\
$7.5 \mathrm{Si} / \mathrm{CaP}$ in acidic solution & $3.72 \pm 0.08$ \\
15Si/CaP in acidic solution & $3.91 \pm 0.03$ \\
\hline
\end{tabular}

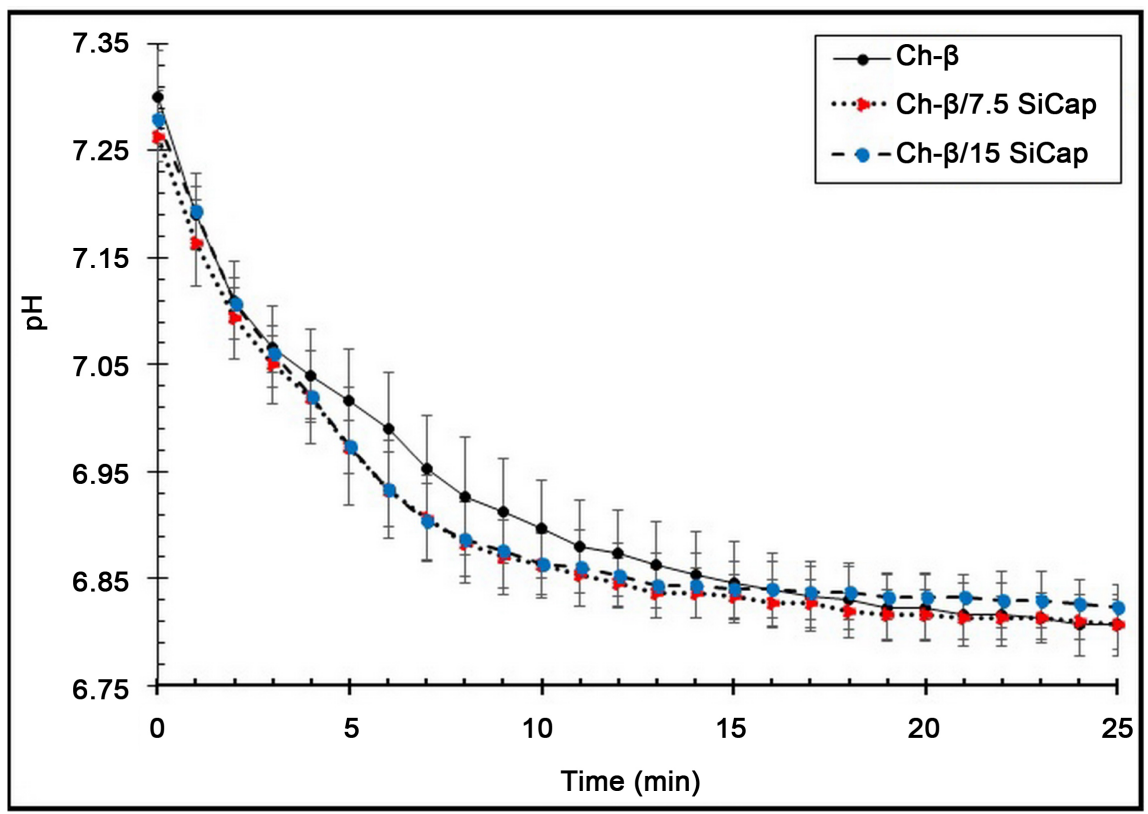

Figure 3. $\mathrm{pH}$ as a function of time, of prepared hydrogels measured at $37^{\circ} \mathrm{C}$ during the sol-gel transition process $(n=3, p>0.05)$.

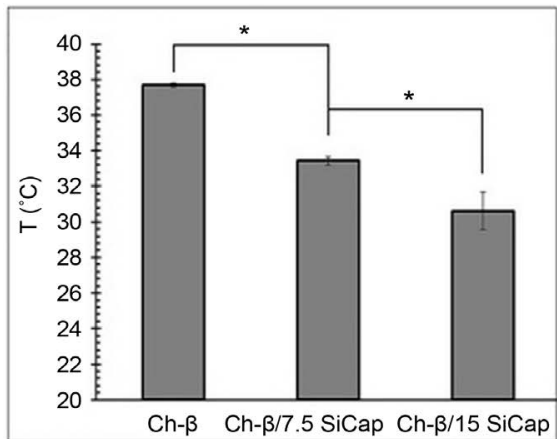

(a)

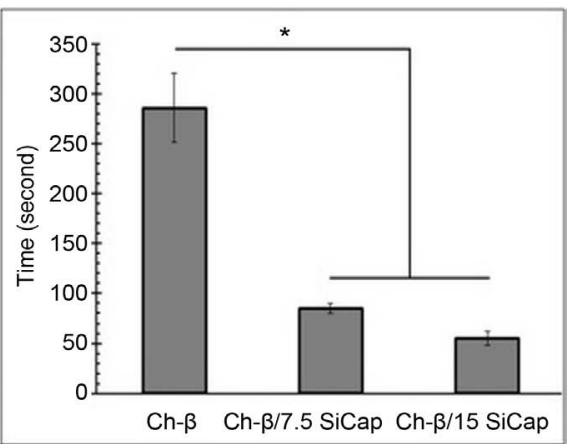

(b)

Figure 4. Gelation temperature (a) and gelation time at $37^{\circ} \mathrm{C}$ (b) of hydrogels based on rheological experiments $\left(\mathrm{n}=3,{ }^{\star} \mathrm{p}<0.05\right)$.

temperature for $\mathrm{Ch}-\beta$, Ch- $\beta / 7.5 \mathrm{SiCaP}$, and $\mathrm{Ch}-\beta / 15 \mathrm{SiCaP}$ hydrogels was $37.69^{\circ} \mathrm{C} \pm$ $0.13^{\circ} \mathrm{C}, 33.44^{\circ} \mathrm{C} \pm 0.24^{\circ} \mathrm{C}$, and $30.62^{\circ} \mathrm{C} \pm 1.05^{\circ} \mathrm{C}$, respectively. Compared with $\mathrm{Ch}-\beta$ hydrogel, the gelation temperature of nanocomposite hydrogels demonstrated a considerable decrease. We also found that adding SiCaP particles into the acidic solution, used to fabricate the nanocomposite hydrogels, increases $\mathrm{pH}$ of that solution. This in turn decreases chitosan concentration. However, pre- 
vious studies suggest that decreasing chitosan concentration increases the gelation temperature of Ch- $\beta$ hydrogel [25]. This paradoxical effect of SiCaP particles on gelation can be attributed to the interaction of bioactive particles with chitosan chains in nanocomposite hydrogels. The possibility of electrostatic attraction between $\left(\mathrm{Si}-\mathrm{O}^{-}\right)$groups on the surface of SiCaPparticles [7] and $\left(\mathrm{NH}_{3}^{+}\right)$ groups of chitosan [4] could decrease electrostatic repulsion force between chitosan chains. Moreover, there is a chance of hydrogen bonding between bioactive particles and chitosan chains that could facilitate attractive hydrophobic interaction between chitosan chains [3] [4]. These phenomena act as important factors that support the vital role of $\beta$ in gelation process [1] [3] [5] of nanocomposite hydrogels. In any case, our results suggest adding SiCaP to Ch- $\beta$ hydrogels decrease gelation temperature.

\subsection{Gelation Time}

Figure 4 (b) shows the gelation time of hydrogels at $37^{\circ} \mathrm{C}$. Gelation time for Ch- $\beta$, Ch- $\beta / 7.5 \mathrm{SiCaP}$, and Ch- $\beta / 15 \mathrm{SiCaP}$ hydrogels was $286 \pm 34 \mathrm{~s}, 85 \pm 5 \mathrm{~s}$, and $55 \pm 7 \mathrm{~s}$, respectively. Gelation time of nanocomposite hydrogels was decreased relative to $\mathrm{Ch}-\beta$ hydrogels. This is most likely due to the decreased gelation temperature of nanocomposite hydrogels [3]. Rapid gelation after injection into a bone defect is important for an injectable thermosensitive hydrogel because it lessens the leakage of hydrogel away from the injection site and increases the therapeutic result [26].

While the concentration of bioactive particles in $\mathrm{Ch}-\beta / 15 \mathrm{SiCaP}$ nanocomposite hydrogel is twice that of the $\mathrm{Ch}-\beta / 7.5 \mathrm{SiCaP}$ nanocomposite hydrogel, there is no significant difference $(p>0.05)$ between the gelation times of these two nanocomposite hydrogels (Figure 4(b)). This may be related to agglomeration of the bioactive particles. That is, by increasing the content of bioactive particles in nanocomposite hydrogels, the possibility of agglomeration increases and reduces the interaction of the bioactive particles with the matrix of nanocomposite hydrogels. Furthermore, lower concentration of chitosan in final Ch- $\beta / 15 \mathrm{SiCaP}$ hydrogel compared to $\mathrm{Ch}-\beta / 7.5 \mathrm{SiCaP}$ hydrogel leads to decreasing the intermolecular interactions and entanglements which would act as a barrier to speed up the gelation process [2] [25].

\subsection{Mechanical Properties of Hydrogels}

Figure 5 shows the estimated Young's modulus of hydrogels. The Young' modulus of Ch- $\beta$, Ch- $\beta / 7.5 \mathrm{SiCaP}$, and Ch- $\beta / 15 \mathrm{SiCaP}$ hydrogels was $1465 \pm 247 \mathrm{~Pa}$, $2992 \pm 271 \mathrm{~Pa}$, and $3352 \pm 304 \mathrm{~Pa}$, respectively.

Compared to the Ch- $\beta$ hydrogel, composite hydrogels showed more than two-fold increase in Young's modulus (Figure 5). Therefore, composite hydrogels with higher Young's modulus are stiffer and have better resistance to deformation by pulling or stretching, which can be attributed to physical (mechanical interlocking) and chemical (electrostatic attraction and hydrogen 


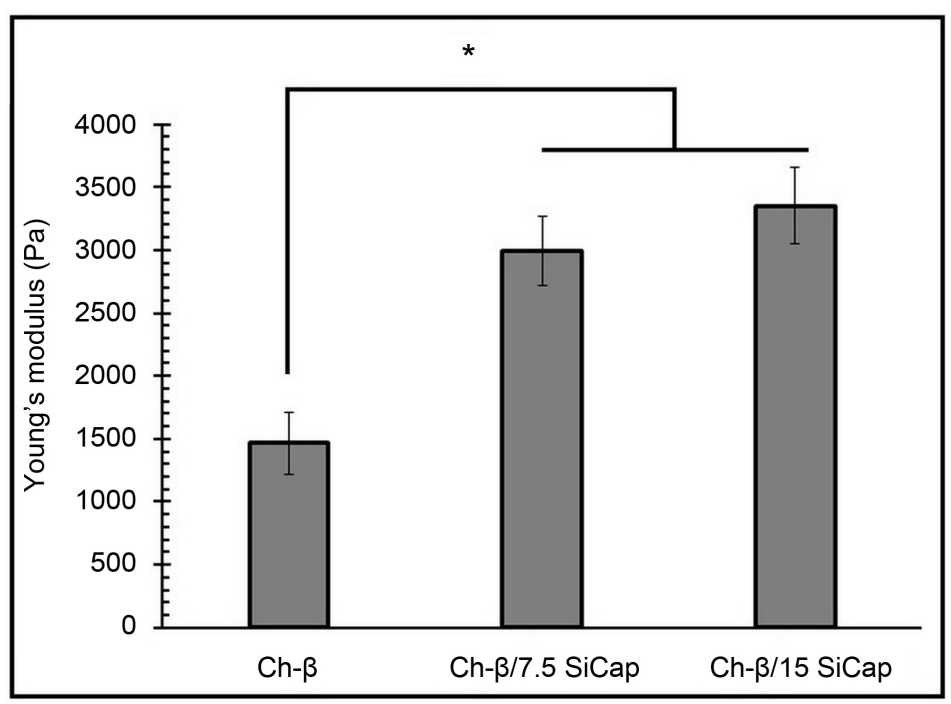

Figure 5. Young's modulus of hydrogels based on rheological experiments $\left(\mathrm{n}=3,{ }^{*} \mathrm{p}<0.05\right)$.

bonding) interactions of the SiCaP bioactive particles with chitosan chains. In fact, the possibility of electrostatic attraction between $\left(\mathrm{Si}-\mathrm{O}^{-}\right)$groups on the surface of SiCaPparticles [7] and $\left(\mathrm{NH}_{3}^{+}\right)$groups of chitosan [4] could decrease electrostatic repulsion force between chitosan chains. Moreover, there is a chance of hydrogen bonding between SiCaPparticles and chitosan chains that could facilitate attractive hydrophobic interaction between chitosan chains [3] [4]. Improving the mechanical strength of composite hydrogels, relative to $\mathrm{Ch}-\beta$ hydrogel, is important as these hydrogels must mechanically support osteogenesis [26]. There was no significant difference $(\mathrm{p}>0.05)$ between the Young's moduli of nanocomposite hydrogels (Ch- $\beta / 7.5 \mathrm{SiCaP}$ and $\mathrm{Ch}-\beta / 15 \mathrm{SiCaP}$ hydrogels). This is likely due to decreasing chitosan concentration and increasing agglomeration of $\mathrm{SiCaP}$ bioactive particles with increasing amounts of these bioactive particles in nanocomposite hydrogels, which limit the interactions of the $\mathrm{SiCaP}$ bioactive particles with chitosan chains.

\subsection{Cytotoxicity}

To demonstrate biocompatibility of prepared hydrogels, an MTT assay was used to quantify hFOB 1.19 cell proliferation. Prepared hydrogels were washed once with SBF and twice with DMEM/F12 before extraction. This washing process increases biocompatibility [17] most probably due to removing the unreacted $\beta$ on the surface or in exposed pores, resulting in reduced $\beta$ concentration of $\mathrm{Ch}-\beta$ hydrogels [2] [17] [27].

Figure 6 shows proliferation of hFOB 1.19 cells after 1, 3, and 5 days exposure to extracts from the three hydrogels and control tissue culture plates. hFOB 1.19 cells treated with extracts from the control (tissue culture plates only) displayed increased proliferation over time $(\# \mathrm{p}<0.05)$. Extracts from hydrogels induced a similar increase in cell proliferation over time $(\# \mathrm{p}<0.05)$ but, except for day 1 , 


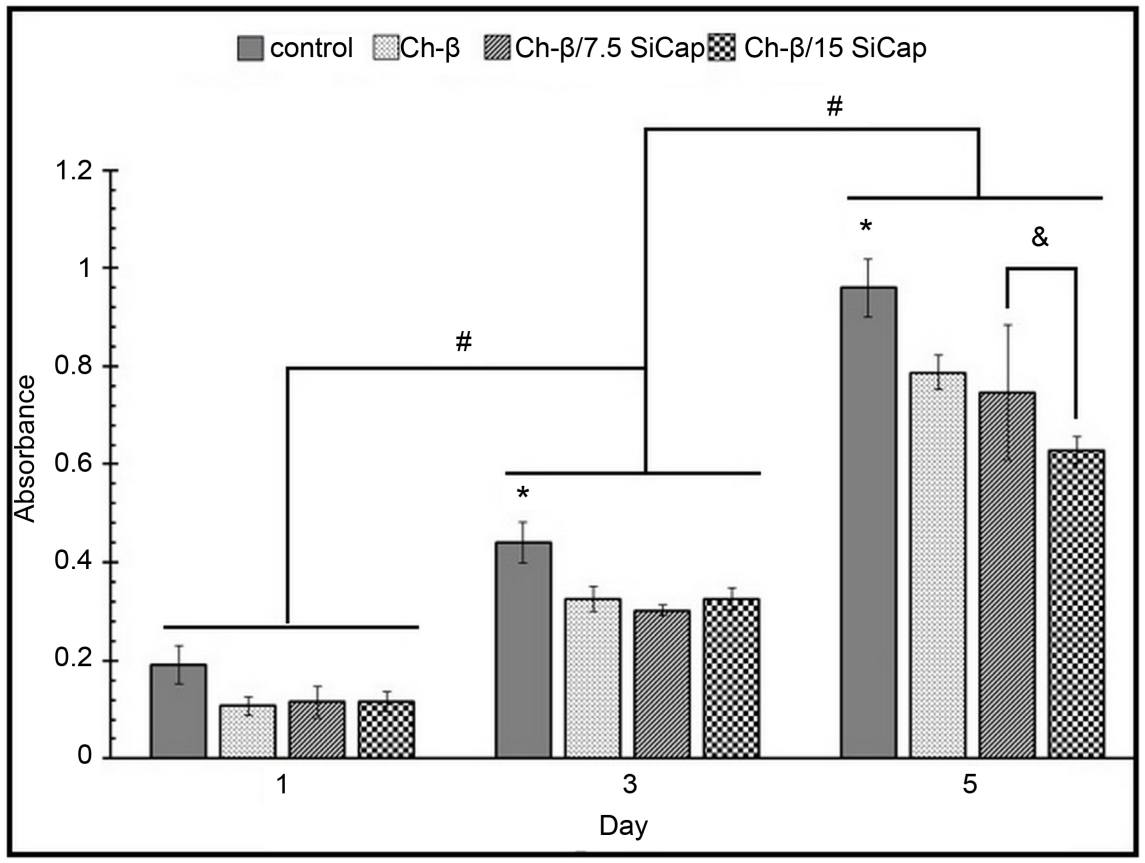

Figure 6. Biocompatibility of prepared hydrogels via MTT assay and hFOB 1.19 cells $(\mathrm{n}=$ $5 ;{ }^{*},{ }^{*}$ and $\left.\& \mathrm{p}<0.05\right)$.

at each day proliferation was significantly less than that of cells exposed to control extracts $\left({ }^{*} \mathrm{p}<0.05\right)$. On the other hand, extracts from $\mathrm{Ch}-\beta$ hydrogels that had added SiCaP bioactive particles had similar effects on proliferation relative to extracts from $\mathrm{Ch}-\beta$ only hydrogels. Thus, adding SiCaP bioactive particles did not make hydrogels more toxic, at least on days 1 and 3. However, after 5 days, exposure to extracts from $\mathrm{Ch}-\beta / 15 \mathrm{SiCaP}$ hydrogels resulted in decreased cell proliferation relative to $\mathrm{Ch}-\beta / 7.5 \mathrm{SiCaP}$ and $\mathrm{Ch}-\beta$ only hydrogels. Chitosan concentration in the final $\mathrm{Ch}-\beta / 15 \mathrm{SiCaP}$ hydrogel was less than that in $\mathrm{Ch}-\beta / 7.5 \mathrm{SiCaP}$ and Ch- $\beta$ only hydrogels due to the higher levels of undissolved chitosan during the fabrication process of the $\mathrm{Ch}-\beta / 15 \mathrm{SiCaP}$ hydrogel which was filtered. Thus, the decreased proliferation of cells exposed to extracts from $\mathrm{Ch}-\beta / 15 \mathrm{SiCaP}$ hydrogel may be a result of increased unreacted $\beta$ which previous studies have shown to decrease cell metabolic activity [28].

\subsection{Alkaline Phosphatase (ALP) Activity}

Based on the cytotoxicity results in section 3.8 , Ch- $\beta / 15 \mathrm{SiCaP}$ hydrogel was removed from further cell studies due to its lower biocompatibility than the Ch- $\beta / 7.5 \mathrm{SiCaP}$ and $\mathrm{Ch}-\beta$ only hydrogels. Figure 7 shows the ALP activity, normalized to total protein, of hFOB 1.19 cells after 2 and 7 days exposure to extracts from the hydrogels (Ch- $\beta / 7.5 \mathrm{SiCaP}$ and $\mathrm{Ch}-\beta$ only hydrogels) and control tissue culture plates.

All extracts induced increased ALP activity over time ( $\left.{ }^{*} \mathrm{p}<0.05\right)$. However, after 7 days, compared to extracts from controls (tissue culture dish only) and hydrogels without SiCaP particles, ALP activity significantly $\left({ }^{*} \mathrm{p}<0.05\right)$ increased 


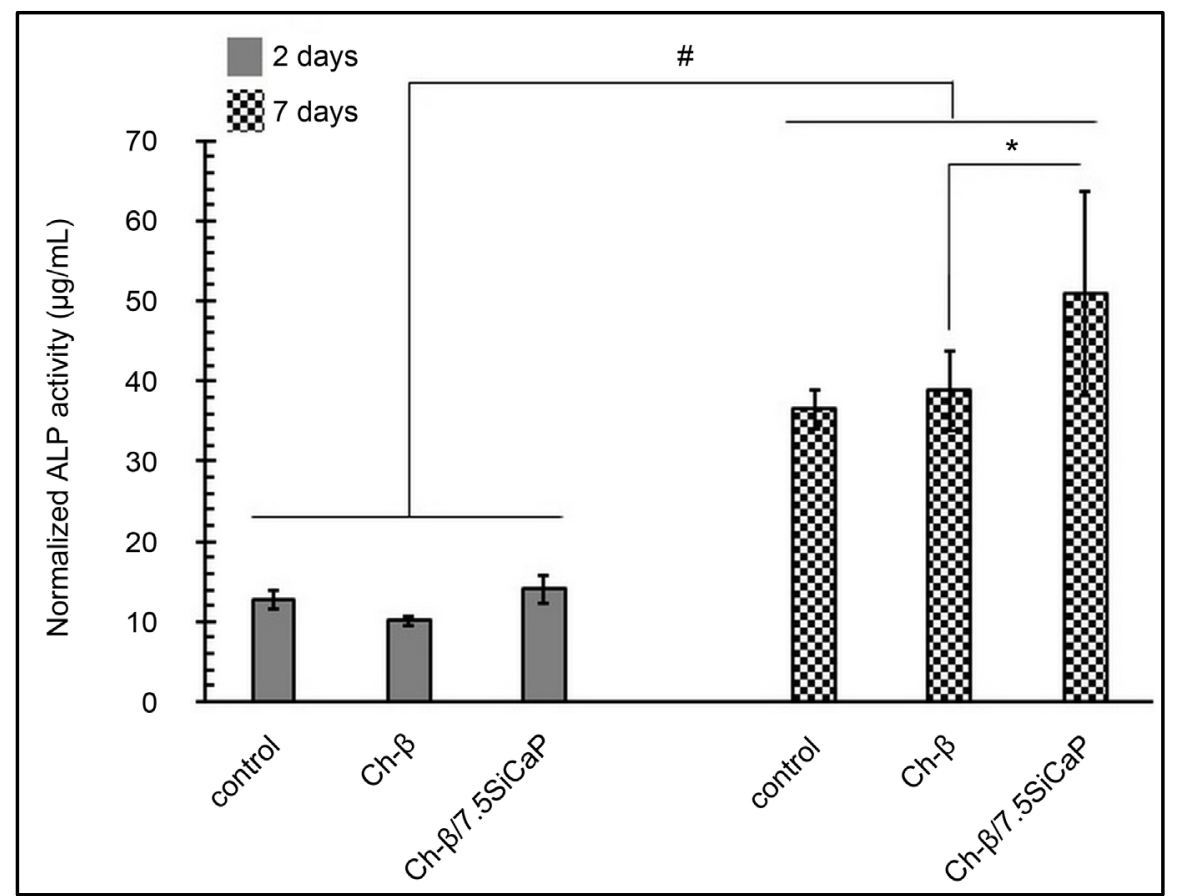

Figure 7. Normalized ALP activity of hFOB 1.19 cells after 2 and 7 days exposure to extracts from the hydrogels and control (tissue culture plates) at $39.5^{\circ} \mathrm{C}\left(\mathrm{n}=5\right.$; $\left.^{*},{ }^{*} \mathrm{p}<0.05\right)$.

in cells cultured in extracts from composite hydrogels. The higher level of osteoblastic cell differentiation induced by extracts from $\mathrm{Ch}-\beta$-GP/7.5SiCaP composite hydrogels could be related to calcium and silicon ions released from these hydrogels which originated from SiCaP particles [7] [8]. It was demonstrated that increasing the calcium ion concentration in cell culture media leads to increased osteoblastic cell differentiation [29] [30]. This fact was attributed to increased bone sialoprotein and osteopontin expression [29] which are important proteins for mediating cell adhesion at the biointerface of a bone graft [31]. Furthermore, it has been shown that the release of silicon into cell culture media leads to increased osteoblastic cell differentiation [32] [33] and collagen-I synthesis [33]. In this case, the enhanced osteoblastic cell differentiation was attributed to increased expression of osteocalcin and osteopontin [32].

\section{Conclusion}

The current study highlights the important role of bioactive SiCaP nanocomposite particles in improving the weaknesses of thermosensitive Ch- $\beta$ hydrogels for orthopedic applications. Compared to the $\mathrm{Ch}-\beta$ hydrogel, the presence of bioactive particles ( $\mathrm{SiCaP}$ ) in nanocomposite hydrogels did not change their $\mathrm{pH}$ but did decrease gelation times and increase stiffnesses. Moreover, compared to the Ch- $\beta$ hydrogel, the presence of SiCaP particles in the Ch- $\beta / 7.5 \mathrm{SiCaP}$ nanocomposite hydrogel did not change its biocompatibility, but improved osteoblastic cell differentiation. Our results suggest that the Ch- $\beta / 7.5 \mathrm{SiCaP}$ nanocomposite hydrogel may offer an innovative approach to bone regeneration. 


\section{Acknowledgements}

This work was supported by the Virginia Commonwealth University College of Engineering Foundation.

\section{Conflicts of Interest}

The authors declare no conflicts of interest regarding the publication of this paper.

\section{References}

[1] Supper, S., Anton, N., Seidel, N., Riemenschnitter, M., Curdy, C. and Vandamme, T. (2014) Thermosensitive Chitosan/Glycerophosphate Based Hydrogel and Its Derivatives in Pharmaceutical and Biomedical Applications. Expert Opinion on Drug Delivery, 11, 249-267. https://doi.org/10.1517/17425247.2014.867326

[2] Ahmadi, R. and Bruijn, J.D.D. (2008) Biocompatibility and Gelation of Chitosan-Glycerol Phosphate Hydrogels. Journal of Biomedical Materials Research Part $A$, 86, 824-832. https://doi.org/10.1002/jbm.a.31676

[3] Chenite, A., Buschmann, M., Wang, D., Chaput, C. and Kandani, N. (2001) Rheological Characterization of Thermogelling Chitosan/Glycerol-Phosphate Solutions. Carbohydrate Polymers, 46, 39-47. https://doi.org/10.1016/S0144-8617(00)00281-2

[4] Chenite, A., Chaput, C., Wang, D., Combes, C., Buschmann, M.D., Hoemann, C.D., Leroux, J.C., Atkinson, B.L., Binette, F. and Selmani, A. (2000) Novel Injectable Neutral Solutions of Chitosan form Biodegradable Gels in Situ. Biomaterials, 21, 2155-2161. https://doi.org/10.1016/S0142-9612(00)00116-2

[5] Zhou, H.Y., Jiang, L.J., Cao, P.P., Li, J.B. and Chen, X.G. (2015) Glycerophosphate-Based Chitosan Thermosensitive Hydrogels and Their Biomedical Applications. Carbohydrate Polymers, 117, 524-536. https://doi.org/10.1016/j.carbpol.2014.09.094

[6] Ganji, F., Abdekhodaie, M.J. and Ramazani, S.A. (2007) Gelation Time and Degradation Rate of Chitosan-Based Injectable Hydrogel. Journal of Sol-Gel Science and Technology, 42, 47-53. https://doi.org/10.1007/s10971-006-9007-1

[7] Latifi, S.M., Fathi, M.H., Sharifnabi, A. and Varshosaz, J. (2017) In Vitro Characterization of a Sol-Gel Derived in Situ Silica-Coated Silicate and Carbonate Co-Doped Hydroxyapatite Nanopowder for Bone Grafting. Materials Science and Engineering. C, 75, 272-278. https://doi.org/10.1016/j.msec.2017.02.078

[8] Latifi, S.M., Fathi, M.H., Varshosaz, J. and Ghochaghi, N. (2016) Simultaneous Structural and Surface Modifications of Nanophase Hydroxyapatite FOR Improving Its Dissolution and Bioactivity. Ceramics International, 42, 6355-6359. https://doi.org/10.1016/j.ceramint.2016.01.029

[9] Zheng, C.Y., Li, S.J., Tao, X.J., Hao, Y.L., Yang, R. and Zhang, L. (2007) Calcium Phosphate Coating of Ti-Nb-Zr-Sn Titanium Alloy. Materials Science and Engineering: $C, 27,824-831$. https://doi.org/10.1016/j.msec.2006.09.021

[10] Gledhill, H.C., Turner, I.G. and Doyle, C. (2001) In Vitro Dissolution Behaviour of Two Morphologically Different Thermally Sprayed Hydroxyapatite Coatings. Biomaterials, 22, 695-700. https://doi.org/10.1016/S0142-9612(00)00232-5

[11] Borum-Nicholas, L. and Wilson Jr., O.C. (2003) Surface Modification of Hydroxyapatite. Part I. Dodecyl Alcohol. Biomaterials, 24, 3671-3679.

https://doi.org/10.1016/S0142-9612(03)00239-4 
[12] Latifi, S.M., Fathi, M.H. and Golozar, H.A. (2011) Preparation and Characterization of Bioactive Hydroxyapatite-Silica Composite Nanopowders via Sol-Gel Method for Medical Applications. Advances in Applied Ceramics, 110, 8-14. https://doi.org/10.1179/174367510X12753884125325

[13] Wan, Y., Creber, K.A.M., Peppley, B. and Bui, V.T. (2003) Ionic Conductivity of Chitosan Membranes. Polymer, 44, 1057-1065.

https://doi.org/10.1016/S0032-3861(02)00881-9

[14] Ta, H.T., Dass, C.R., Larson, I., Choong, P.F.M. and Dunstan, D.E. (2009) A Chitosan-Dipotassium Orthophosphate Hydrogel for the Delivery of Doxorubicin in the Treatment of Osteosarcoma. Biomaterials, 30, 3605-3613.

https://doi.org/10.1016/j.biomaterials.2009.03.022

[15] Kloxin, A.M., Benton, J.A. and Anseth, K.S. (2010) In Situ Elasticity Modulation with Dynamic Substrates to Direct Cell Phenotype. Biomaterials, 31, 1-8.

https://doi.org/10.1016/j.biomaterials.2009.09.025

[16] Mabry, K.M., Lawrence, R.L. and Anseth, K.S. (2015) Dynamic Stiffening of Poly(ethylene glycol)-Based Hydrogels to Direct Valvular Interstitial Cell Phenotype in a Three-Dimensional Environment. Biomaterials, 49, 47-56.

https://doi.org/10.1016/j.biomaterials.2015.01.047

[17] Dang, Q.F., Yan, J.Q, Lin, H., Chen, X.G., Liu, C.S., Ji, Q.X. and Li, J.J. (2012) Design and Evaluation of a Highly Porous Thermosensitive Hydrogel with Low Gelation Temperature as a 3D Culture System for Penaeus chinensis Lymphoid Cells. Carbohydrate Polymers, 88, 361-368. https://doi.org/10.1016/j.carbpol.2011.12.014

[18] Balasundaram, G., Sato, M. and Webster, T.J. (2006) Using Hydroxyapatite Nanoparticles and Decreased Crystallinity to Promote Osteoblast Adhesion Similar to Functionalizing with RGD. Biomaterials, 27, 2798-2805.

https://doi.org/10.1016/j.biomaterials.2005.12.008

[19] Khan, T.A., Peh, K.K. and Chng, H.S. (2002) Reporting Degree of Deacetylation Values of Chitosan: The Influence of Analytical Methods. Journal of Pharmacy \& Pharmaceutical Sciences, 5, 205-212.

[20] Queiroz, M.F., Melo, K.R.T., Sabry, D.A., Sassaki, G.L. and Rocha, H.A.O. (2015) Does the Use of Chitosan Contribute to Oxalate Kidney Stone Formation? Marine Drugs, 13, 141-158. https://doi.org/10.3390/md13010141

[21] Song, C., Yu, H., Zhang, M., Yang, Y. and Zhang, G. (2013) Physicochemical Properties and Antioxidant Activity of Chitosan from the Blowfly Chrysomya megacephala Larvae. International Journal of Biological Macromolecules, 60, 347-354. https://doi.org/10.1016/j.ijbiomac.2013.05.039

[22] Dash, M., Chiellini, F., Ottenbrite, R.M. and Chiellini, E. (2011) Chitosan-A Versatile Semi-Synthetic Polymer in Biomedical Applications. Progress in Polymer Science, 36, 981-1014. https://doi.org/10.1016/j.progpolymsci.2011.02.001

[23] Berger, J., Reist, M., Mayer, J.M., Felt, O., Peppas, N.A. and Gurny, R. (2004) Structure and Interactions in Covalently and Ionically Crosslinked Chitosan Hydrogels for Biomedical Applications. European Journal of Pharmaceutics and Biopharmaceutics, 57, 19-34. https://doi.org/10.1016/S0939-6411(03)00161-9

[24] Dang, Q., Liu, K., Zhang, Z., Liu, C., Liu, X., Xin, Y., Cheng, X., Xu, T., Cha, D. and Fan, B. (2017) Fabrication and Evaluation of Thermosensitive Chitosan/Collagen/ $\beta$ Glycerophosphate Hydrogels for Tissue Regeneration. Carbohydrate Polymers, 167, 145-157. https://doi.org/10.1016/j.carbpol.2017.03.053

[25] Cho, J., Heuzey, M.C., Begin, A., Pierre, J. and Carreau, P.J. (2006) Chitosan and Glycerophosphate Concentration Dependence of Solution Behaviour and Gel Point 
Using Small Amplitude Oscillatory Rheometry. Food Hydrocolloids, 20, 936-945. https://doi.org/10.1016/j.foodhyd.2005.10.015

[26] Ngoenkam, J., Faikrua, A., Yasothornsrikul, S. and Viyoch, J. (2010) Potential of an Injectable Chitosan/Starch/ $\beta$-Glycerol Phosphate Hydrogel for Sustaining Normal Chondrocyte Function. International Journal of Pharmaceutics, 391, 115-124. https://doi.org/10.1016/j.ijpharm.2010.02.028

[27] Wang, L. and Stegemann, J.P. (2010) Thermogelling Chitosan and Collagen Composite Hydrogels Initiated with $\beta$-Glycerophosphate for Bone Tissue Engineering. Biomaterials, 31, 3976-3985. https://doi.org/10.1016/j.biomaterials.2010.01.131

[28] Dang, Q.F., Zou, S.H., Chen, X.G., Liu, C.S., Li, J.J., Zhou, X., Liu, Y. and Cheng, X.J. (2012) Characterizations of Chitosan-Based Highly Porous Hydrogel: The Effects of the Solvent. Journal of Applied Polymer Science, 125, e88-e98. https://doi.org/10.1002/app.36681

[29] Jung, G.Y., Park, Y.J. and Han, J.S. (2010) Effects of HA Released Calcium Ion on Osteoblast Differentiation. Journal of Materials Science: Materials in Medicine, 21, 1649-1654. https://doi.org/10.1007/s10856-010-4011-y

[30] Ma, S., Yang, Y., Carnes, D.L., Kim, K., Park, S., Oh, S.H. and Ong, J.L. (2005) Effects of Dissolved Calcium and Phosphorous on Osteoblast Responses. Journal of Oral Implantology, 31, 61-67. https://doi.org/10.1563/0-742.1

[31] Bernards, M.T., Qin, C., Ratner, B.D. and Jiang, S. (2008) Adhesion of MC3T3-E1 Cells to Bone Sialoprotein and Bone Osteopontin Specifically Bound to Collagen I. Journal of Biomedical Materials Research Part A, 86, 779-787. https://doi.org/10.1002/jbm.a.31650

[32] Gupta, G., Kirakodu, S. and El-Ghannam, A. (2010) Effects of Exogenous Phosphorus and Silicon on Osteoblast Differentiation at the Interface with Bioactive Ceramics. Journal of Biomedical Materials Research Part A, 95, 882-890. https://doi.org/10.1002/jbm.a.32915

[33] Reffitt, D.M., Ogston, N., Jugdaosingh, R., Cheung, H.F.J., Evans, B.A.J., Thompson, R.P.H., Powel, J.J. and Hampson, G.N. (2003) Orthosilicic Acid Stimulates Collagen Type 1 Synthesis and Osteoblastic Differentiation in Human Osteoblast-Like Cells in Vitro. Bone, 32, 127-135. https://doi.org/10.1016/S8756-3282(02)00950-X 